\title{
Direct cost analysis for patients with severe asthma receiving omalizumab treatment
}

\author{
๑Hale Ateş, $₫$ Kurtuluş Aksu, @Özlem Özdedeoğlu, @Buket Başa Akdoğan, @İlkay Koca Kalkan, \\ ๑Gözde Köycü Buhari, @Ferda Öner Erkekol \\ Atatürk Chest Disease and Chest Surgery Training and Research Hospital, Department of Allergy and Immunology, Ankara, Turkey
}

Cite this article as: Ateş H, Aksu K, Özdedeoğlu Ö, et al. Direct cost analysis for patients with severe asthma receiving omalizumab treatment. J Health Sci Med 2021; 4(5): 735-740.

\begin{abstract}
Aim: The present study aims to reveal a direct cost analysis of patients with severe allergic asthma receiving omalizumab treatment.

Material and Method: Twenty-two adults with severe allergic asthma who were treated with omalizumab and were routinely checked on the $16^{\text {th }}$ week, $1^{\text {st }}$ year, and $3^{\text {rd }}$ year of treatment were included in the study. Clinical and demographic features of subjects were retrospectively documented before and after omalizumab treatment as well as pharmaceutical, emergency and hospital costs.

Results: The monthly treatment cost per patient was higher during the $16^{\text {th }}$ week, $1^{\text {st }}$ year, and $3^{\text {rd }}$ year $(€ 411.80 \pm 190.84$, $€ 409.7 \pm 211.57, € 404.2 \pm 157.30$ respectively) when compared with the pre-treatment period $(€ 107.91 \pm 48.62)(\mathrm{p}<0.001)$. Similarly, monthly emergency visit cost per patient at 16 thweek, $1^{\text {st }}$ year, and $3^{\text {rd }}$ year of omalizumab treatment $(€ 0.03 \pm 0.13$, $€ 0.19 \pm 0.51, € 0.56 \pm 0.41$ respectively), as well as the monthly hospitalization cost per patient at $16^{\text {th }}$ week, $1^{\text {st }}$ year, and $3^{\text {rd }}$ year of omalizumab treatment $(€ 1.44 \pm 5.57, € 1.50 \pm 5.27, € 16.3 \pm 13.8$ respectively) were both lower compared to pre-treatment period $(€ 1.82 \pm 1.23$ and $€ 17.69 \pm 10.84$ respectively) ( $\mathrm{p}<0.001$ for both). A statistically significant drop was observed in the frequency of asthma exacerbations as well as emergency visits, hospitalizations and number of patients receiving systemic corticosteroid with omalizumab treatment. An improvement was also detected in asthma control test scores, forced expiratory volume in 1 second, and peak expiratory flow values of patients compared to the baseline values.

Conclusion: Omalizumab treatment is clinically effective and although it adds an extra pharmaceutical cost to the patients' management it reduces the emergency and hospital costs.
\end{abstract}

Keywords: Asthma management, severe asthma, cost analysis, omalizumab

\section{INTRODUCTION}

Asthma is a serious community health problem that affects 200-300 million individuals worldwide $(1,2)$ and causes approximately 250,000 deaths annually (3). Severe asthma accounts for 5-10\% of all asthma cases (4). From the perspective of the usage of health services, it is known that severe asthma opens the gateway to higher medication costs, an increased rate of emergency visits, and a higher rate of hospitalization compared to cases involving mild or moderate asthma (5). This indicates that there is a link between the severity of asthma and serious financial problems for patients (6).

A limited number of Turkish studies have shown that as the severity of asthma increases, relevant costs increase. Çelik et al. (7) found that the direct annual cost of asthma was about $\$ 1,465$ per patient, while the direct annual cost of severe asthma was about $\$ 3,491$ per patient. Bavbek et al. found that the annual cost per patient with uncontrolled asthma was more than twice the annual cost per patient with controlled asthma (8). In the same study, the authors showed that the cost varied greatly depending on the attack severity (mild attack: $€ 128.60$, moderate attack: $€ 172.60$, severe attack: $€ 308.20)(8)$. As discussed above, severe asthma is a clinical condition that causes a considerable increase in cost, poorer quality of life, loss of productivity at work, and a decreased number of attack-free periods. For these reasons, new agents have been introduced for the treatment of severe asthma, one of which is omalizumab. 
Omalizumab is a humanized recombinant DNA derivative as well as a human IgG1k monoclonal antibody that specifically binds free IgE in blood and interstitial fluid (9). Omalizumab treatment was licensed in Turkey in 2008 for the management of severe allergic asthmatics patients if disease control is not achieved despite high-dose inhaled corticosteroid treatment. Clinical studies and real-life data show that omalizumab leads to a significant reduction in asthma attacks, unplanned physician visits, emergency visits, and hospitalizations as well as a significant increase in quality of life for patients with severe asthma (10-15).

While there is a limited number of studies investigating the cost-effectiveness of omalizumab, they have revealed contradictory results. Omalizumab was not found to be cost-effective in one study hailing from Canada (16), whereas it was found to be cost-effective in another study hailing from Brazil (17). However, as of yet there is no Turkish-based studies regarding cost analysis of omalizumab. The present study aims to reveal treatment costs as well as clinical parameters in severe allergic asthmatics before and after omalizumab treatment.

\section{MATERIAL AND METHOD}

This study was approved by Ankara Keçiören Training and Research Hospital Clinical Researchs Ethics Committee (Date: 12.27. 2017, Decision:1553). All procedures were carried out in accordance with the ethical rules and the principles of the Declaration of Helsinki.

\section{Study Population and Design}

This retrospective study was planned in the allergy and immunology clinic at Atatürk Chest Disease and Chest Surgery Training and Research Hospital between January $1^{\text {st }}$-and April 1 $1^{\text {st }}, 2018$. Adults with severe allergic asthma who have treated with omalizumab after a follow-up for at least one year in our clinic between 2008 and 2015 were included in the study. Patients with missing data regarding spirometric values, asthma control test (ACT) scores, record of asthma exacerbations, emergency visits and hospitalizations in hospital files were excluded from the study.

Patients' demographic characteristics, comorbid conditions, atopy status, omalizumab dose, administration interval, pre- and post-treatment ( $16^{\text {th }}$ week, $1^{\text {st }}$ year, and $3^{\text {rd }}$ year) forced expiratory volume in 1 second $\left(\mathrm{FEV}_{1}\right)$, peak expiratory flow (PEF) and $\mathrm{FEV}_{1} / \mathrm{FVC}$ (forced vital capacity) values, ACT scores, number of asthma attacks, number of emergency visits, number of hospitalizations, medications and drug doses were recorded from their patients' files.

\section{Omalizumab Administration Protocol}

Omalizumab is administered in subjects with asthma if disease control was not achieved with high-dose inhaled corticosteroid plus long-acting beta2 agonist and/or leukotriene receptor antagonists, with a skin test or specific IgE positivity to at least one perennial allergen (house dust mite, cat-dog hair, cockroaches or mold spores) and with a total serum IgE level between 30-1500 IU/mL. Omalizumab treatment was administered subcutaneously every two or four weeks with doses and dosing frequencies determined according to baseline serum total IgE level and body weight (18). At $16^{\text {th }}$ week after commencing treatment clinical response was evaluated according to symptoms, reliever drug use, frequency of exacerbations and asthma control (10). The treatment is maintained with the same dose in patients who benefit from the treatment, and is terminated in patients who do not.

\section{Evaluation of the Cost}

The cost of all medications used by the patients before and after treatment (including omalizumab) was specified as the 'direct medical cost'. The average amount invoiced in cases where the patient had visited the emergency room and was hospitalized due to asthma was calculated based on the current cost information received from the accounting department within our hospital. The 'hospitalization cost' was calculated as the hospital cost+the pharmacy cost. The 'total cost' was calculated as being the direct medical cost + the total emergency room cost+the total hospitalization cost. All costs were calculated as being the total monthly cost and monthly cost per patient. The medical costs (medications regularly used by the patient and omalizumab) and hospital costs were calculated based on the pricing stipulated in the Turkish Social Security Institution's Communique on Medical Practices. The costs as calculated in Turkish Liras (TRY) were converted to Euros using the mid-term exchange rate in 2018, which was TRY 5.66.

\section{Statistical Analysis}

The Statistical Package for Social Sciences (SPSS) for Windows 20 (IBM SPSS Inc., Chicago, USA) was used for statistical assessments. The normal distribution of the data was evaluated using the Kolmogorov-Smirnov test. Values with a normal distribution were presented as being the mean \pm standard deviation and values without normal distribution were presented as being the median (min$\max$ ). Categorical variables were presented as numbers and percentages. The differences between pre- and posttreatment follow-ups were evaluated using the mixed model analysis in repeating samples. $\mathrm{P}<0.05$ was considered to be statistically significant in the statistical analysis.

\section{RESULTS}

Table 1 shows the demographic characteristics of the patients. The study population consisted of 22 patients, including $12(54.5 \%)$ males and $10(45.5 \%)$ females. 
$72.7 \%$ of the patients had rhinitis-nasal polyposis, $13.6 \%$ had drug allergies, $77.3 \%$ were sensitive to house dust mites, $22.7 \%$ were sensitive to cat-dog hair, $45.5 \%$ were sensitive to mold, $22.7 \%$ were sensitive to cockroaches, and $\% 22.7$ were sensitive to pollen.

The average pre-treatment body weight among the patients was $81.6 \pm 16.2 \mathrm{~kg}$ (min-max: 49-110), and the median total IgE was $218 \mathrm{IU} / \mathrm{ml}$ (min-max: 31-990). The median omalizumab dose was $300 \mathrm{mg}$ (min-max: 150600 ) and the median monthly total omalizumab dose was 375 mg (min-max: 150-1200).

\begin{tabular}{|lc|}
\hline \multicolumn{2}{|l|}{ Table 1. Demographic and clinical findings of patients } \\
\hline Variables & $\mathbf{n}(\%)$ \\
\hline Gender & \\
$\quad$ Male & $12(54.5)$ \\
\hline Female & $10(45.5)$ \\
Rhinitis-nasal polyp & $16(72.7)$ \\
Drug allergy & $3(13.6)$ \\
Urticaria angioedema & $1(4.5)$ \\
Other & \\
Anemia+OSAS & $1(4.5)$ \\
Hypertension & $1(4.5)$ \\
Hypertension+OSAS & $1(4.5)$ \\
Chronic sinusitis & $2(9.1)$ \\
Latex allergy & $1(4.5)$ \\
Obesity & $1(4.5)$ \\
OSAS & $2(9.1)$ \\
Osteoporosis+Thrombocytopenia & $1(4.5)$ \\
Reflux & $1(4.5)$ \\
Reflux+Hypertension & $1(4.5)$ \\
Reflux+Hypertension+ OSAS & $1(4.5)$ \\
Reflux+Venous insufficiency & $1(4.5)$ \\
Ulcer & $1(4.5)$ \\
House dust mite sensitization & $17(77.3)$ \\
Cat-dog sensitization & $5(22.7)$ \\
Mold sensitization & $10(45.5)$ \\
Cockroach sensitization & $5(22.7)$ \\
Pollen sensitization & $5(22.7)$ \\
\hline Categorical variables were shown as number (\%). \\
Abbreviations: OSAS: Obstructive sleep apnea syndrome
\end{tabular}

While the average post-treatment $\mathrm{FEV}_{1}(\%)$ level, PEF(\%) level, and ACT scores of the patients were significantly higher compared to the pre-treatment period $(\mathrm{p}=0.005, \mathrm{p}=0.003$, and $\mathrm{p}<0.001$ respectively ), they did not show a significant difference between follow-ups (16th week, $1^{\text {st }}$ year, and $3^{\text {rd }}$ year). There was no significant difference between any of the follow-ups before or after the treatment in terms of the average $\mathrm{FEV}_{1}(\mathrm{ml})$, average PEF $(\mathrm{ml})$, and average $\mathrm{FEV}_{1} / \mathrm{FVC}$ ratio (Table 2).

Table 3 shows the change in the number of attacks, emergency visits, hospitalizations, and cost distribution between the pre- and post-treatment period in detail.

The average cost of emergency visits per patient was lower in all of post-treatment follow-ups compared to the pre-treatment period, while it was higher in the $3^{\text {rd }}$ year compared to the $16^{\text {th }}$ week and the $1^{\text {st }}$ year $(\mathrm{p}<0.001)$. The average total hospitalization cost per patient among those who were hospitalized was lower in the $16^{\text {th }}$ week and $1^{\text {st }}$ year compared to the pre-treatment period $(p<0.001)$, while no significant difference was found between the $3^{\text {rd }}$ year and the pre-treatment period. The average total pre-treatment cost of the patients was found to be significantly lower compared to the average total post-treatment cost $(\mathrm{p}<0.001)$. Despite this, no significant difference between the post-treatment follow-up periods $\left(16^{\text {th }}\right.$ week, $1^{\text {st }}$ year, and $3^{\text {rd }}$ year) in terms of the average total cost was found (Figure).

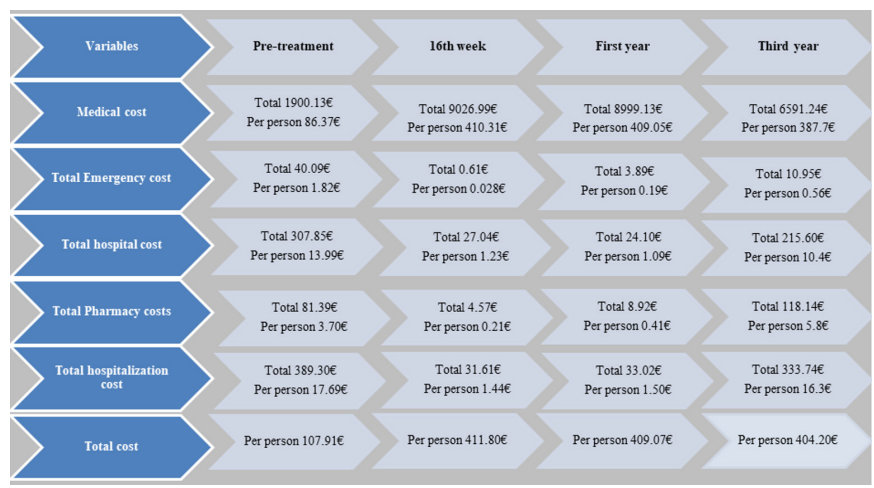

Figure. Cost diagram before and after treatment

\section{Table 2. Changes in pulmonary function tests and asthma control before and after Omalizumab treatment}

\begin{tabular}{|c|c|c|c|c|c|}
\hline Variables & $\begin{array}{c}\underset{n=22}{\text { Pre-treatment }} \\
\text { the }\end{array}$ & $\begin{array}{c}16^{\text {th }} \text { week } \\
n=22\end{array}$ & $\begin{array}{c}\begin{array}{c}\text { First year } \\
\mathbf{n}=22\end{array}\end{array}$ & $\begin{array}{c}\text { Third year } \\
\mathbf{n}=17\end{array}$ & $\mathbf{p}$ \\
\hline $\mathrm{FEV}_{1}(\%)$ & $69.5 \pm 18.8$ & $82.5 \pm 18.3$ & $83 \pm 19.6$ & $78.6 \pm 22.4$ & $0.005^{*}$ \\
\hline $\mathrm{FEV}_{1}(\mathrm{ml})$ & $2286.4 \pm 743.5$ & $2535.9 \pm 865.9$ & $2525.5 \pm 824.9$ & $2245.9 \pm 891.1$ & 0.306 \\
\hline PEF (\%) & $71.2 \pm 23.3$ & $81.4 \pm 23.5$ & $83.1 \pm 24.7$ & $80.2 \pm 25.9$ & $0.003^{*}$ \\
\hline PEF (ml) & $5745 \pm 1994.6$ & $6256.4 \pm 2238.2$ & $6192.3 \pm 2016.7$ & $5652.9 \pm 2345.7$ & 0.209 \\
\hline $\mathrm{FEV}_{1} / \mathrm{FVC}$ ratio & $76.5 \pm 7.8$ & $80.3 \pm 6.7$ & $80 \pm 11.3$ & $75.6 \pm 10.2$ & 0.327 \\
\hline ACT (score) & $11.4 \pm 2.9$ & $22 \pm 2.2$ & $22.2 \pm 3.2$ & $22.3 \pm 4.6$ & $<0.001^{\star}$ \\
\hline
\end{tabular}




\begin{tabular}{|c|c|c|c|c|c|}
\hline Variables & $\begin{array}{c}\text { Pre-treatment } \\
n=22\end{array}$ & $\begin{array}{c}16^{\text {th }} \text { week } \\
n=22\end{array}$ & $\begin{array}{c}\text { First year } \\
n=22\end{array}$ & $\begin{array}{c}\text { Third year } \\
n=17\end{array}$ & $\mathbf{p}$ \\
\hline Direct medical cost $(€)$ & 1900.13 & 9026.99 & 8999.13 & 6591.24 & \\
\hline Average cost per person $(€)$ & $86.37 \pm 30.44$ & $410.31 \pm 268.30$ & $409.05 \pm 267.40$ & $387.7 \pm 194.53$ & $<0.001^{\star}$ \\
\hline Number of patients suffering from attack, $n(\%)$ & $13(59.1)$ & $3(13.6)$ & $6(27.3)$ & $10(58.8)$ & $0.007^{*}$ \\
\hline Total number of attacks (n) & 37 & 3 & 8 & 24 & - \\
\hline Average number of attacks per person (n) & $2.0 \pm 1.7$ & $0.1 \pm 0.4$ & $0.4 \pm 0.7$ & $1.5 \pm 1.4$ & $0.001^{*}$ \\
\hline Number of patients admitted to emergency, n (\%) & $8(36.4)$ & $1(4.5)$ & $4(18.1)$ & $7(41.2)$ & $0.020^{*}$ \\
\hline Total number of emergency applications (n) & 20 & 1 & 4 & 15 & - \\
\hline Average number of emergency applications per person (n) & $2.5 \pm 1.9$ & $0.1 \pm 0.2$ & $0.2 \pm 0.5$ & $1.1 \pm 1.0$ & $0.003^{*}$ \\
\hline Total Emergency cost $(€)$ & 40.09 & 0.61 & 3.89 & 10.95 & - \\
\hline Average Emergency cost per person $(€)$ & $1.82 \pm 1.23$ & $0.03 \pm 0.13$ & $0.19 \pm 0.51$ & $0.56 \pm 0.41$ & $<0.001^{*}$ \\
\hline Total number of hospitalizations (n) & 17 & 2 & 3 & 11 & - \\
\hline Average number of hospitalizations per person (n) & $1.6 \pm 0.8$ & $0.1 \pm 0.3$ & $0.1 \pm 0.4$ & $0.8 \pm 1.0$ & $<0.001^{\star}$ \\
\hline Total hospital cost $(€)$ & 307.85 & 27.04 & 24.10 & 215.60 & - \\
\hline Average cost of hospital per person $(€)$ & $14.0 \pm 8.75$ & $1.23 \pm 4.62$ & $1.09 \pm 3.72$ & $10.4 \pm 9.1$ & $<0.001^{*}$ \\
\hline Total Pharmacy costs $(€)$ & 81.39 & 4.57 & 8.92 & 118.14 & - \\
\hline Average pharmacy cost per person $(€)$ & $3.70 \pm 2.59$ & $0.21 \pm 0.98$ & $0.41 \pm 1.60$ & $5.8 \pm 4.9$ & $<0.001^{\star}$ \\
\hline Total hospitalization cost $(€)$ & 389.30 & 31.61 & 33.02 & 333.74 & - \\
\hline Average total hospitalization cost per person $(€)$ & $17.69 \pm 10.84$ & $1.44 \pm 5.57$ & $1.50 \pm 5.27$ & $16.3 \pm 13.8$ & $<0.001^{\star}$ \\
\hline Total cost per person $(€)$ & $107.91 \pm 48.62$ & $411.80 \pm 190.84$ & $409.7 \pm 211.57$ & $404.2 \pm 157.30$ & $<0.001^{\star}$ \\
\hline
\end{tabular}

There was a significant decrease in the rate of patients experiencing attacks in the $16^{\text {th }}(13.6 \%)$ and the $1^{\text {st }}$ year (27.3\%) compared to the pre-treatment period (59.1\%). Moreover, there was a significant increase in the rate of patients experiencing attacks in the $3^{\text {rd }}$ year $(58.8 \%)$ compared to the $16^{\text {th }}$ week and the $1^{\text {st }}$ year and it was similar to the rate of patients experiencing attacks in the pre-treatment period $(\mathrm{p}=0.007)$. While the average number of attacks among these patients showed a significant difference in the $16^{\text {th }}$ week and the $1^{\text {st }}$ year post-treatment $(\mathrm{p}=0.001)$, it was similar in the $3^{\text {rd }}$ year post-treatment and the pre-treatment period.

There was a significant decrease in the rate of patients visiting emergency room in the $16^{\text {th }}$ week $(4.5 \%)$ and the $1^{\text {st }}$ year $(18.1 \%)$ post-treatment compared to the pre-treatment period (36.4\%). The average number of emergency room visits among these patients was lower in all post-treatment follow-ups compared to the pretreatment period $(\mathrm{p}=0.003)$.

There was a significant decrease in the rate of hospitalization in all post-treatment follow-ups compared to the pre-treatment period. While there was a significant increase in the rate of hospitalization in the $3^{\text {rd }}$ year compared to the $16^{\text {th }}$ week and the $1^{\text {st }}$ year post-treatment, it was lower compared to the pretreatment period $(p<0.001)$. The average number of hospitalizations among these patients was lower in all of the post-treatment follow-up periods compared to the pre-treatment period. Even though omalizumab use led to a significant increase in medical cost, the number of attacks did decrease by $91.9 \%$ in the $16^{\text {th }}$ week, $78.4 \%$ in the $1^{\text {st }}$ year, and $35.1 \%$ in the $3^{\text {rd }}$ year post-treatment compared to the pre-treatment period. The number of emergency room visits decreased by $95 \%$ in the $16^{\text {th }}$ week, $80 \%$ in the $1^{\text {st }}$ year and $25 \%$ in the $3^{\text {rd }}$ year post-treatment compared to the pre-treatment period. The number of hospitalizations decreased by $88.2 \%$ in the $16^{\text {th }}$ week post-treatment, $82.3 \%$ in the $1^{\text {st }}$ year post-treatment, and $35.3 \%$ in the $3^{\text {rd }}$ year post-treatment compared to the pre-treatment period.

The ratio of the patients receiving systemic steroid therapy was at its highest before treatment, it was found to significantly decrease in the $16^{\text {th }}$ week and the 1st year, and to increase in the $3^{\text {rd }}$ year compared to the $16^{\text {th }}$ week and the $1^{\text {st }}$ year; however, it still was significantly lower compared to the pre-treatment period $(\mathrm{p}<0.001)$. Median systemic steroid dose was not significantly different in $16^{\text {th }}$ week, $1^{\text {st }}$ year, and $3^{\text {rd }}$ year after treatment and before treatment $[690 \mathrm{mg}(160-5171)$ versus $120 \mathrm{mg}$ (16$678)$ versus $400 \mathrm{mg}(80-3200)$ versus $506 \mathrm{mg}$ (40-2656), respectively; $\mathrm{p}=0.187$.

\section{DISCUSSION}

In our study, the monthly total cost per patient was higher in the $16^{\text {th }}$ week, $1^{\text {st }}$ year, and $3^{\text {rd }}$ year posttreatment compared to the pre-treatment period. The increase in the total post-treatment cost was largely caused by the increase in the direct medical cost. The 
direct medical cost, in turn, increased largely due to the cost of omalizumab itself. The monthly emergency visit cost per patient as well as the monthly hospitalization cost per patient in the $16^{\text {th }}$ week, $1^{\text {st }}$ year, and $3^{\text {rd }}$ year post-treatment was lower compared to the pre-treatment period. This study is the first to investigate this subject in Turkey. A serious drop was observed in the monthly number of attacks, emergency visits, hospitalizations, and patients using systemic steroids following treatment with Omalizumab. An increase was observed in ACT, $\mathrm{FEV}_{1}$, and PEF values.

If we review other studies available in the literature, in a Polish study, Jahnz-Różyk et al. (19) found that the hospitalization cost per patient, the cost of emergency room visit, the number of office visits, and the dose of oral corticosteroids had decreased, while the total treatment cost increased. The researchers highlighted that this increase was largely due to the cost of omalizumab. In a Japanese study, omalizumab was not found to be costeffective for patients with severe asthma and the authors suggested that cost-effectiveness could be achieved by lowering the price of omalizumab(20). Similarly, in an American study, omalizumab was not found to be costeffective in patients with allergic asthma patients, whereby this was attributed to the high price of omalizumab (21). In a Canadian study, similarly to the above studies, Tadrous et al. (16) had found that omalizumab was not cost-effective in patients suffering from either moderate or severe asthma. Likewise, similar to the above-mentioned studies, the total cost after omalizumab treatment was found to be higher than the total cost before the treatment in our study. Conversely, we observed a dramatic decrease in the number of attacks, the number of emergency room visits, and the hospitalization costs during the post-treatment period. We believe that this may be associated with the high price of omalizumab, similar to what was observed in Japan and Poland, as well as associated with the low average emergency room visit fees and hospitalization costs in Turkey - the latter give that Turkey has lower average emergency and hospitalization costs compared to both the United States and much of Europe. Unlike our and the other aforementioned studies, it was shown in other studies from Ireland, Spain, Italy, Brazil, the Netherlands, and the United States that the omalizumab was both costeffective and that led to a considerably lower number of hospitalizations, the number of emergency room visits, loss of productivity at work, oral corticosteroid use, and the number of outpatient clinic visits. Also, a marked increase was observed in $\mathrm{FEV}_{1}$ and PEF values and quality of life (17,22-27).

When the data of the patients in our study, whose asthma control was unexpectedly deteriorated in the 3rd year and who had an increase in the number of attacks, emergency admissions, and therefore the hospitalization cost, were re-examined, it was observed that systemic steroid use was discontinued at the end of the $1^{\text {st }}$ year in most of these asthmatic patients who were well controlled with omalizumab treatment. As a result, worsening of asthma may have been observed in the later periods of the patients. Our study consists of the analysis of real-life data, and the outcome of the patients was like this.

In a handful of other studies, it was emphasized that the omalizumab treatment had to be administered to select groups of patients suffering from severe asthma for it to be cost-effective as well as effective for clinical recovery $(28,29)$.

The most significant limitation of our study is its retrospective design. The study was performed using the information available in patients' files. For this reason, this descriptive study provides an estimation of costs and outcomes for a defined patient group. Provided that our data did not allow for the calculating of the quality-adjusted life-year (QALY) and the incremental cost-effectiveness ratio (ICER), this study is related to the direct cost of omalizumab rather than the analysis of its cost-effectiveness. Nevertheless, we can say that it is clinically effective given that leads to a lower number of attacks, emergency room visits, and hospitalization rates. The lack of $3^{\text {rd }}$ year follow-up data for some patients is also another limitation of our study. One of the important limitations of our study is that indirect cost (payments for missed workdays covered by the employee's disability and sick-leave program), could not be calculated.

\section{CONCLUSION}

We found that the addition of omalizumab to the treatment regime of patients diagnosed with severe allergic asthma led to a serious increase in the total posttreatment cost. Yet, we also observed a decrease in the average emergency room visit and hospitalization costs after the omalizumab treatment. We believe that reducing omalizumab prices in our country would provide a direct cost reduction in severe allergic asthma patients. Furthermore, prospective studies involving a greater number of patients are needed to better examine the direct cost analysis of omalizumab in the Turkish context.

\section{ETHICAL DECLARATIONS}

Ethics Committee Approval: This study was approved by Ankara Keçiören Training and Researchs Hospital Clinical Research Ethics Committee (Date: 12.27. 2017, Decision:1553).

Informed Consent: Because the study was designed retrospectively, no written informed consent form was obtained from patients. 
Referee Evaluation Process: Externally peer-reviewed. Conflict of Interest Statement: The authors have no conflicts of interest to declare.

Financial Disclosure: The authors declared that this study has received no financial support.

Author Contributions: All of the authors declare that they have all participated in the design, execution, and analysis of the paper, and that they have approved the final version.

\section{REFERENCES}

1. Beasley R, of Asthma TIS. Worldwide variation in prevalence of symptoms of asthma, allergic rhinoconjunctivitis, and atopic eczema: ISAAC. The Lancet 1998; 351: 1225-32.

2. Sekerel BE, Türktas H, Bavbek S, Öksüz E, Malhan S. Economic burden of pediatric asthma in Turkey: A Cost of Illness Study from payer perspective. Turk Thorac J 2020; 21: 248.

3. D'Amato G, Vitale C, Molino A, et al. Asthma-related deaths. Multidiscip Respir Med 2016; 11: 37.

4. Pakhale S, Mulpuru S, Boyd M. Optimal management of severe/ refractory asthma. Clin Med Insights Circ Respir Pulm Med 2011, 5: 37-47.

5. Adams RJ, Smith BJ, Ruffin RE. Factors associated with hospital admissions and repeat emergency department visits for adults with asthma. Thorax 2000; 55: 566-73.

6. Bavbek S, Malhan S, Mungan D, et al. Economic burden of severe asthma in Turkey: a cost of illness study from payer perspective. Eur Ann Allergy Clin Immunol 2021; 53: 128-37.

7. Çelik GE, Bavbek S, Paşaoğlu G, et al. Direct medical cost of asthma in Ankara, Turkey. Respiration 2004; 71: 587-93.

8. Bavbek S, Mungan D, Türktaş H, et al. A cost-of-illness study estimating the direct cost per asthma exacerbation in Turkey. Respir Med 2011; 105: 541-8.

9. Schulman ES. Development of a monoclonal antiimmunoglobulin E antibody (omalizumab) for the treatment of allergic respiratory disorders. Am J Respir Crit Care Med 2001; 164: 6-11.

10.Lai T, Wang S, Xu Z, et al. Long-term efficacy and safety of omalizumab in patients with persistent uncontrolled allergic asthma: a systematic review and meta-analysis. Sci Rep 2015; 5: $1-10$.

11. Bousquet J, Cabrera P, Berkman N, et al. The effect of treatment with omalizumab, an anti-IgE antibody, on asthma exacerbations and emergency medical visits in patients with severe persistent asthma. Allergy 2005; 60: 302-8.

12. Chipps B, Buhl R, Beeh K-M, et al. Improvement in quality of life with omalizumab in patients with severe allergic asthma. Curr Med Res Opin 2006; 22: 2201-8.

13. Korn S, Thielen A, Seyfried S, et al. Omalizumab in patients with severe persistent allergic asthma in a real-life setting in Germany. Respir Med 2009; 103: 1725-31.

14. Bavbek S, Aydın O, Kepil SÖ, et al. Therapy with omalizumab in patients with severe persistent allergic asthma: a real life data in Turkey. Tuberk Toraks 2010; 58: 425-34.

15. Yorgancioğlu A, Öner Erkekol F, Mungan D, et al. Long-Term omalizumab treatment: a multicenter, real-life, 5-year trial. Int Arch Allergy Immunol 2018; 176: 225-33.

16. Tadrous M, Khuu W, Lebovic G, et al. Real-world health care utilization and effectiveness of omalizumab for the treatment of severe asthma. Ann Allergy Asthma Immunol 2018; 120: 59-65.
17.Suzuki C, Lopes da Silva N, Kumar P, Pathak P, Ong SH. Costeffectiveness of omalizumab add-on to standard-of-care therapy in patients with uncontrolled severe allergic asthma in a Brazilian healthcare setting. J Med Econ 2017; 20: 832-9.

18. Hochhaus G, Brookman L, Fox H, et al. Pharmacodynamics of omalizumab: implications for optimised dosing strategies and clinical efficacy in the treatment of allergic asthma. Curr Med Res Opin 2003; 19: 491-9.

19.Jahnz-Różyk K, Lis J, Warchoł M, Kucharczyk A. Clinical and economic impact of a one-year treatment with omalizumab in patients with severe allergic asthma within a drug programme in Poland. BMC Pulm Med 2018; 18: 48

20. Morishima T, Ikai H, Imanaka Y. Cost-effectiveness analysis of omalizumab for the treatment of severe asthma in Japan and the value of responder prediction methods based on a multinational trial. Value Health Reg Issues 2013; 2: 29-36.

21. Wu AC, Paltiel AD, Kuntz KM, Weiss ST, Fuhlbrigge AL. Costeffectiveness of omalizumab in adults with severe asthma: results from the Asthma Policy Model. J Allergy Clin Immunol 2007; 120: 1146-52.

22. Costello R, Long D, Gaine S, et al. Therapy with omalizumab for patients with severe allergic asthma improves asthma control and reduces overall healthcare costs. Irish J Med Sci 2011; 180: 637-41.

23. Dal Negro RW, Tognella S, Pradelli L. A 36-month study on the cost/utility of add-on omalizumab in persistent difficult-to-treat atopic asthma in Italy. J Asthma 2012; 49: 843-8.

24.van Nooten F, Stern S, Braunstahl G-J, et al. Cost-effectiveness of omalizumab for uncontrolled allergic asthma in the Netherlands. J Med Econ 2013; 16: 342-8.

25.Levy AN, García a Ruiz AJ, García-Agua Soler N, Sanjuan MVH. Cost-effectiveness of omalizumab in severe persistent asthma in Spain: a real-life perspective. J Asthma 2015; 52: 205-10.

26. del Carmen Vennera M, Valero A, Uría E, Forné C, Picado C. Cost-effectiveness analysis of omalizumab for the treatment of severe persistent asthma in real clinical practice in Spain. Clin Drug Investig 2016; 36: 567-78.

27. Campbell J, Spackman D, Sullivan S. The costs and consequences of omalizumab in uncontrolled asthma from a USA payer perspective. Allergy 2010; 65: 1141-8.

28. Faria R, McKenna C, Palmer S. Optimizing the position and use of omalizumab for severe persistent allergic asthma using costeffectiveness analysis. Value Health 2014; 17 : 772-82.

29. Oba Y, Salzman GA. Cost-effectiveness analysis of omalizumab in adults and adolescents with moderate-to-severe allergic asthma. J Allergy Clin Immunol 2004; 114: 265-9. 